\title{
Effects of industrial gas impurities on the performance of mixed matrix membranes
}

Shinji Kanehashi, ${ }^{1,2}$ Alita Aguiar, ${ }^{1}$ Hiep Lu, ${ }^{1}$ G. Chen, ${ }^{1}$ and Sandra Kentish $* 1$

${ }^{\mathbf{1}}$ Peter Cook Centre for Carbon Capture and Storage Research, Department of Chemical Engineering, The University of Melbourne, Victoria 3010, Australia

${ }^{2}$ Graduate of School of Engineering, Tokyo University of Agriculture and Technology, 2-24-16 Nakacho, Koganei, 184-8588, Japan

* Correspondence to Sandra E. Kentish

Tel : +61-3-8344-6682, Fax : +61-8344-4153

E-mail : sandraek@unimelb.edu.au 


\begin{abstract}
A series of mixed matrix membranes using a commercially available aromatic polyimide (Matrimid ${ }^{\circledR} 5218$ ) with nanoparticles formed from carbon, a porous organic polymer and metal organic frameworks were prepared to investigate the effects of flue gas impurities on gas permeation. We show that common impurities found in power station flue gases $\left(\mathrm{H}_{2} \mathrm{~S}, \mathrm{SO}_{2}\right.$, and NO) have significant effects upon the performance of these mixed matrix membranes. The effects of $\mathrm{NO}, \mathrm{SO}_{2}$ and $\mathrm{H}_{2} \mathrm{~S}$ on the zeolitic imidazolate framework $\mathrm{ZIF}-8$ are all large and rapid and would render these membranes unsuitable for flue gas service that do not use flue gas desulfurisation. Similarly, $\mathrm{H}_{2} \mathrm{~S}$ adsorbs irreversibly into membranes containing copper benzene-1,3,5-tricarboxylate (Cu-BTC), although the impacts of $\mathrm{NO}$ and $\mathrm{SO}_{2}$ are less severe. The membranes containing a porous organic polymer or porous carbon are less affected by these contaminants. In particular, the permeability of the membrane containing the porous organic polymer is still significantly above that of the base Matrimid polymer after exposure for 80 days to $1000 \mathrm{ppm}$ of each contaminant. Further, this mixed matrix structure shows enhanced $\mathrm{H}_{2} \mathrm{~S}$ selectivity. These results suggest that MMMs prepared using organic based nanoparticles can be effective in gas separation applications such as natural gas sweetening, biogas purification and post-combustion carbon capture, when acid gases are present as an impurity.
\end{abstract}

Keywords: Hydrogen sulfide; sulfur dioxide; nitric oxide; carbon dioxide capture. 


\section{INTRODUCTION}

It has been demonstrated that the addition of nanoparticles to form mixed matrix membranes (MMMs) can increase the permeability and/or selectivity of polymeric membranes [1-4] and can reduce membrane aging [5-7]. These MMMs can potentially be applied to industrial $\mathrm{CO}_{2}$ separation applications such as $\mathrm{CO}_{2}$ capture from flue gases (pre and post combustion), natural gas purification and biogas upgrading.

However, industrial gas streams are not the pure component mixtures tested in laboratories, but can contain water vapor, hydrocarbons, aromatic compounds, and acid gases as major impurities [8]. Flue gas streams in post-combustion capture applications are typically saturated with water and contain 200-5000 ppm sulphur oxide $\left(\mathrm{SO}_{\mathrm{x}}\right)$ and $150-300$ ppm $\left(\mathrm{NO}_{\mathrm{x}}\right)$, with nitric oxide (NO) the major component and less than $10 \mathrm{ppm}$ nitrogen dioxide $\left(\mathrm{NO}_{2}\right)$ [9]. The use of flue gas desulfurization can reduce these concentrations to $<10 \mathrm{ppm}$ SOx and remove $90 \%$ of the $\mathrm{NO}_{\mathrm{x}}[10]$, but such processes are not always used, particularly in Australia and China. Hydrogen sulfide $\left(\mathrm{H}_{2} \mathrm{~S}\right)$ is also present at up to $10,000 \mathrm{ppm}$ in natural gas sweetening [11], $5000 \mathrm{ppm}$ in iron blast furnace exhausts[12], 500-1000 ppm in precombustion flue gases[13] and 10,000 ppm in biogas streams[14].

The presence of these components may compete with $\mathrm{CO}_{2}$ for sorption sites resulting in a decrease in permeability, they may degrade the base polymer [15] or they may react with the nanoparticles themselves. Copper based metal organic frameworks (MOFs) such as copper benzene-1,3,5-tricarboxylate (Cu-BTC, also known as HKUST-1) are known to react with $\mathrm{H}_{2} \mathrm{~S}$ to form copper sulfide [16]. Ethiraj et al. [17] noted that exposure to $\mathrm{H}_{2} \mathrm{~S}$ at 2-6 $\mathrm{kPa}$ caused the formation of a covallite $\mathrm{CuS}$ phase and consequent destruction of the framework of Cu-BTC. Conversely, these authors find that the zeolitic imidazolate framework, ZIF-8 (Basolite Z1200) is quite stable in the presence of $0.5 \mathrm{kPa}$ of $\mathrm{H}_{2} \mathrm{~S}$, with some structural distortion at 2-6 kPa. Similarly, Liu et al.[18] show that $\mathrm{H}_{2} \mathrm{~S}$ adsorption to ZIF-8 is physical 
and readily reversible. Anderson et al. [19] found that nanoporous carbon membranes were relatively stable in the presence of $0.3 \mathrm{kPa}$ of $\mathrm{H}_{2} \mathrm{~S}$, with less than $30 \%$ loss in permeability at $35^{\circ} \mathrm{C}$ and minimal reductions in selectivity. Scholes et al. [20] note a $10 \%$ loss of $\mathrm{CO}_{2}$ permeability when the polymer Matrimid ${ }^{\circledR} 5218$ was exposed to $0.5 \mathrm{kPa} \mathrm{H}_{2} \mathrm{~S}$ at $35^{\circ} \mathrm{C}$.

Peterson et al. [21] find no interaction between $\mathrm{Cu}-\mathrm{BTC}$ and $\mathrm{SO}_{2}$, noting no deleterious effects [22]. $\quad \mathrm{Yu}$ et al.[23] find that $\mathrm{SO}_{2}$ adsorbs more strongly than $\mathrm{CO}_{2}$ in $\mathrm{Cu}-\mathrm{BTC}$, both in the absence and presence of humidity. Molecular simulations suggest that $\mathrm{Cu}-\mathrm{BTC}$ adsorbs about twice the amount of $\mathrm{SO}_{2}$ than ZIF-8 $[24,25]$, as the pore size for this second material is too small to admit the $\mathrm{SO}_{2}$ molecule[25]. However, significant sorption does not occur until the $\mathrm{SO}_{2}$ partial pressure exceeds $10 \mathrm{kPa}$ in both cases [25]. Hu et al. use simulations to indicate that the presence of $\mathrm{H}_{2} \mathrm{O}, \mathrm{SO}_{2}$ has negligible effect on $\mathrm{CO}_{2}$ adsorption and $\mathrm{CO}_{2} / \mathrm{N}_{2}$ separation in ZIF-8 [26]. Bhattacharyya et al. [27] similarly find that $\mathrm{H}_{2} \mathrm{O}$ and $\mathrm{SO}_{2}$ in isolation do not affect ZIF-8, but note that the use of 10-20 ppm concentrations of $\mathrm{SO}_{2}$ in a humid environment $(85 \% \mathrm{RH})$ at ambient pressure leads to irreversible structural degradation over time due to attack by sulfuric and sulfurous acid species.

$\mathrm{NO}_{2}$ is also known to react with the $\mathrm{Cu}$ in $\mathrm{Cu}-\mathrm{BTC}$ leading to the formation of copper nitrate [28]. Xu et al. [29] show that ZIF-8 adsorbs more $\mathrm{NO}_{2}$ at $70 \% \mathrm{RH}$ than in a dry gas stream due to the formation of $\mathrm{NO}_{2} \cdot x \mathrm{H}_{2} \mathrm{O}$ hydrates and can displace sorbed water molecules from the crystal.

The impact of these gases within a MMM format remains unknown. Here we study the effect of acid gases on the $\mathrm{CO}_{z}$-separation permeability of MMMs constructed from a common polyimide but containing a variety of nanoparticles including a porous carbon, a porous organic polymer, $\mathrm{Cu}-\mathrm{BTC}$ and ZIF-8. The use of processing conditions consistent with those of a post-combustion, natural gas purification, or biogas upgrading process provides an indication of membrane performance under such conditions. 


\section{EXPERIMENTAL}

\section{Membrane Preparation}

Mixed matrix membranes with a nanoparticle loading of $20 \mathrm{wt} \%$ were fabricated using commercially available aromatic polyimide, Matrimid ${ }^{\circledR} 5218$ as a host matrix. The loading of nanoparticle was calculated based on the following equation;

$$
\text { Filler loading }(\mathrm{wt} \%)=\frac{w_{\text {filler }}}{w_{\text {polymer }}+w_{\text {filler }}} \times 100
$$

where $w_{\text {polymer }}$ and $w_{\text {filler }}$ are weight of polymer and filler, respectively. The Matrimid was supplied by Huntsman Advanced Materials America. In the present work, four nanoparticle fillers were used. Graphitised mesoporous carbon and zeolitic imidazolate framework (ZIF8, Basolite Z1200) were purchased from Sigma-Aldrich. Copper benzene-1,3,5tricarboxylate $\left(\mathrm{Cu}-\mathrm{BTC}\left(\left[\mathrm{Cu}_{3}(\mathrm{BTC})_{2}\right]_{3} \mathrm{H}_{2} \mathrm{O}\right.\right.$, HKUST-1) was synthesized according to the method presented in the Supplementary information of Xiao et al.(2013)[30]. A porous organic polymer (POP-2) was synthesized according Hua et al. (2014) [31]. The hydrophobic amorphous POP-2 contains triarylamines linked by 1,4-diethynylphenyl bridges [31]. All materials used in this work were dried at $100^{\circ} \mathrm{C}$ overnight under vacuum to remove moisture before use. Mixed matrix membranes were prepared as described elsewhere $[32,33]$. The thickness of the well-dried membranes was on average $60-80 \mu \mathrm{m}$, as measured by a micrometer. The physical properties of the nanoparticles, polyimide and MMMs have been reported in our previous work $[32,33]$.

\section{Gas permeation}

Pure gas permeation measurements were performed based on the constantvolume/variable-pressure method (CVVP) while the constant-pressure/variable-volume (CPVV) approach was used for gas mixtures. The equipment was designed and built in-house 
as reported in previous work $[34,35]$.

$\mathrm{CO}_{2}$ is known to plasticise the membrane structure, leading to increased permeability and reduced selectivity. For this reason, the permeability of $\mathrm{N}_{2}$ and $\mathrm{CH}_{4}$ was used to evaluate the impact of the acid gases over time, as these gases do not themselves alter performance. The initial membrane performance was first determined using pure $\mathrm{CH}_{4}$ and $\mathrm{N}_{2}$ at $35^{\circ} \mathrm{C}$ and 2 bar absolute pressure. The feed gas was then changed to $1000 \mathrm{ppm} \mathrm{H}_{2} \mathrm{~S}, 1000 \mathrm{ppm} \mathrm{NO}$ or 1000 ppm $\mathrm{SO}_{2}$ in $\mathrm{N}_{2}$ (Coregas Thomastown, Australia) at $35^{\circ} \mathrm{C}$ and 7.5 bar $(0.75 \mathrm{kPa}$ of the contaminant). An FTIR-Gas cell was used to determine the concentration of $\mathrm{NO}$ and $\mathrm{SO}_{2}$ in the permeate stream according to international standards[36]. The concentration of $\mathrm{CH}_{4}, \mathrm{~N}_{2}$, and $\mathrm{H}_{2} \mathrm{~S}$ was determined using gas chromatography. Gas permeation measurements were conducted every 60 min until the equilibrium steady state was achieved.

Membrane samples were then exposed to these flue gas mixtures for up to 80 days at 7.5 Bar total pressure $(0.75 \mathrm{kPa}$ of the contaminant). This was achieved by placing the membranes in a sealed container that was first evacuated and then filled with the relevant gas mixture to a pressure of 7.5 bar. The membranes were removed for permeability testing in pure nitrogen at regular intervals. It should be noted that during these testing intervals, the membranes would also be exposed to ambient oxygen and humidity for short periods. Membrane regeneration of aged membranes by thermal treatment was also investigated, by exposure to $100^{\circ} \mathrm{C}$ for 24 hours and $200^{\circ} \mathrm{C}$ for 24 hours under vacuum.

\section{Characterization}

The membrane density $(\rho)$ was determined based on the Archimedean principle using an analytical balance (Mettler Toledo $\mathrm{AB} 204-5)$ at room temperature $\left(23 \pm 1^{\circ} \mathrm{C}\right)[9,37]$. Three separate samples were tested to ensure the accuracy of this measurement. Wide-angle Xray diffraction (WAXD) measurements were performed on a D8 advance (Bruker, Germany) at 
5 seconds per step of $0.02^{\circ}$ using a Ni-filtered $\mathrm{CuK} \alpha$ radiation source at $40 \mathrm{kV}$ and $30 \mathrm{~mA}$. The dispersion angle was between 5 and $50^{\circ}$. Nitrogen adsorption-desorption measurements of the nanoparticles were conducted on a ASAP2010 (Micromeritics, USA) apparatus at $77 \mathrm{~K}$. The internal surface area was then calculated by the BET method.

\section{RESULTS AND DISCUSSION}

\section{Gas permeation}

The nitrogen permeability of fresh membranes was first tested for mixtures of 1000 ppm NO, $\mathrm{SO}_{2}$ and $\mathrm{H}_{2} \mathrm{~S}$ in nitrogen (Figure $z$ 1). For the pure Matrimid polymer, there is a slight increase in $\mathrm{N}_{2}$ permeability when $\mathrm{NO}$ and $\mathrm{H}_{2} \mathrm{~S}$ are both present. While this may reflect only experimental error, it may also indicate plasticization of the membrane structure - this is often reported for polymers exposed to $\mathrm{H}_{2} \mathrm{~S}$ [38]. The decline in permeability in the presence of $\mathrm{SO}_{2}$ probably reflects competitive adsorption, where the $\mathrm{SO}_{2}$ displaces $\mathrm{N}_{2}$ from adsorption sites given its much higher critical temperature (431K versus $126 \mathrm{~K})$. Within the mixed matrix membranes, all three penetrants result in a net decline in permeability. $\mathrm{H}_{2} \mathrm{~S}$ clearly has the greatest effect upon permeability. This is somewhat surprising, as competitive adsorption is usually related to the critical temperature of the penetrant. This scales as $\mathrm{NO}(180 \mathrm{~K})<\mathrm{H}_{2} \mathrm{~S}$ $(373.2 \mathrm{~K})<\mathrm{SO}_{2}(430.8 \mathrm{~K})[39]$.

The permeability of the penetrants $\mathrm{SO}_{2}$ and $\mathrm{NO}$ through these membranes was too low to be detected, given the low feed concentration. However, it was possible to determine the $\mathrm{H}_{2} \mathrm{~S}$ permeability (Table 1). It is apparent that the permeability of $\mathrm{H}_{2} \mathrm{~S}$ through the pure polymer is significantly greater than that of $\mathrm{CH}_{4}$ and $\mathrm{N}_{2}$. This reflects its higher critical temperature (higher solubility), as the kinetic diameter of all three molecules are comparable. Conversely, it is only half the permeability of $\mathrm{CO}_{2}$, which has a smaller kinetic diameter and hence can diffuse more rapidly. As expected, the $\mathrm{H}_{2} \mathrm{~S}$ permeability increases with the addition 
of MOF or POP nanoparticles due to the increase in free volume within the membrane. The exception is for the membrane containing $\mathrm{Cu}$-BTC. In this case, no $\mathrm{H}_{2} \mathrm{~S}$ could be detected in the permeate, suggesting a very low permeability. This may be because the $\mathrm{H}_{2} \mathrm{~S}$ was adsorbing irreversibly inside these MOFs, preventing any permeation. This is consistent with our observations of the color changes of this membrane (Figure 12 ). As noted in the Introduction, similar changes have been reported in the literature following exposure of $\mathrm{Cu}$ BTC to $\mathrm{H}_{2} \mathrm{~S}$, reflecting the formation of copper sulfide $[16,17,28,40]$.

In our previous work, we have shown that the addition of nanoparticles to Matrimid causes an increase in gas permeability, with very little change in selectivity [32]. Conversely, the selectivity of the membranes containing the organic nanoparticles POP-2 and carbon towards $\mathrm{H}_{2} \mathrm{~S}$ appears to increase relative to the base Matrimid. In particular, the result for a MMM containing POP-2 in Matrimid provides a membrane with very high permeability and selectivity towards $\mathrm{H}_{2} \mathrm{~S}$ when tested in a $\mathrm{H}_{2} \mathrm{~S} / \mathrm{N}_{2}$ mixture. The increased selectivity probably arises from the strong sorption of the $\mathrm{H}_{2} \mathrm{~S}$ molecule to these nanoparticles, which in turn reduces the nitrogen adsorption through competitive effects. This mixed matrix structure may thus have potential for $\mathrm{H}_{2} \mathrm{~S}$ removal from gas streams. The selectivity towards $\mathrm{H}_{2} \mathrm{~S}$ when $\mathrm{ZIF}-8$ is present falls substantially. This suggests that the $\mathrm{H}_{2} \mathrm{~S}$ is significantly affecting the structure of these mixed matrix membranes. This result is more evident from the aging results presented in the next section.

\section{Membrane aging}

There was no change in either $\mathrm{N}_{2}$ or $\mathrm{CH}_{4}$ permeability for any MMM or for the base Matrimid over at least 40 days of exposure to pure $\mathrm{N}_{2}$, within experimental error. Similarly, the pure Matrimid membranes were quite stable in mixtures of $1000 \mathrm{ppm}_{2} \mathrm{~S}$ and $\mathrm{NO}$ over at least 60 days of aging (Figures 3 and 4). There was a slight loss in in permeability (less than 5\%) 
when Matrimid was aged in $\mathrm{SO}_{2}$ (Figure 5). While there was no obvious change in $\mathrm{CH}_{4}$ or $\mathrm{N}_{2}$ permeability, a slight decrease in membrane density of Matrimid at the end of the experiment (Figure 6) from 1.223 to $1.199 \mathrm{~g} / \mathrm{cm}^{3}$ (2\% decrease) supports the theory that some plasticisation due to $\mathrm{H}_{2} \mathrm{~S}$ occurred [41].

Conversely, all of the membranes containing nanoparticles showed reduced permeability over time (Figures 3-5). The membranes containing POP-2 lost around 50\% of their permeability in the presence of all three impurities over a period of around 3-6 weeks. However, importantly the final steady state permeability of POP-2 is still greater than that of the pure Matrimid in all cases, indicating that these mixed matrix structures still have potential for flue gas applications. There is no change in the final density of the POP-2 MMM (Figure 6) when exposed to any impurity, which suggests that there has been no change to the nanoparticle structure. The greatest decline in permeance for the POP-2 structure occurred in the presence of NO. This is the least condensable of the three penetrants, so the results suggest that the loss of permeance in this case relates to a chemical reaction between the penetrant and the nanoparticle, rather than a physical interaction. In the case of NO, this may be caused by the presence of small quantities of the more reactive $\mathrm{NO}_{2}$ in the gas, both due to impurities in the original $\mathrm{NO}-\mathrm{N}_{2}$ gas mixture $\left(1 \% \mathrm{NO}_{2}\right.$ in total $\left.\mathrm{NO}_{\mathrm{x}}\right)$ and possibly due to oxidation of residual NO with ambient oxygen during the testing process. Similar results are found for membranes containing nanoporous carbon, although as this nanoparticle adds less free volume to the fresh membrane, the permeability falls essentially to the level of the pure Matrimid control after aging in these gas mixtures. This means that there is little incentive to add this particular nanoparticle once long-term performance is considered.

Conversely, for the membrane containing $\mathrm{Cu}-\mathrm{BTC}, \mathrm{H}_{2} \mathrm{~S}$ has a more dramatic effect upon $\mathrm{N}_{2}$ permeability (Figure 3 ), with performance falling to that of the base Matrimid in around two weeks. This is consistent with the permeability results (Table 1) where $\mathrm{H}_{2} \mathrm{~S}$ was 
not observed to permeate the membrane, indicating irreversible adsorption. The rate of permeability decline for $\mathrm{SO}_{2}$ and $\mathrm{NO}$ is comparable to that of POP-2, but it continues until the permeability is comparable to that of the base Matrimid. Further, for all three penetrants, there is a clearer increase in membrane density after aging, indicating that the MOF structure is collapsing. As noted above, these changes are consistent with prior reports that these nanoparticles are unstable in the presence of $\mathrm{H}_{2} \mathrm{~S}$ and $\mathrm{NO}_{2}$.

Finally, all three penetrants have a dramatic impact upon the membranes containing ZIF-8 (Figures 3-5). In all cases, the permeability falls to very low levels within a week. Interestingly, the permeability clearly falls below that of the base Matrimid. This indicates that not only have the ZIF-8 structures collapsed, in doing so they have blocked pathways through the underlying polymer matrix. The collapse in the structure is again reflected in the substantial increases in membrane density also recorded (Figure 6). The density results for ZIF-8 would suggest that $\mathrm{SO}_{2}$ causes the greatest impact upon MOF structure. Conversely, XRD results show the greatest loss in MOF crystallinity for both $\mathrm{H}_{2} \mathrm{~S}$ and $\mathrm{SO}_{2}$ (Figure 7). The membrane ZIF-8 exposed to NO shows only small losses in crystallinity, even though the change in density is one of the greatest. The differences may be related to differences in the way the crystal structures collapse into amorphous regions and the extent to which irreversible adsorption of penetrants itself adds to membrane density.

These results are not consistent with those of other workers [17, 18, 26, 29] who generally find that ZIF-8 is quite stable in the presence of $\mathrm{H}_{2} \mathrm{~S}, \mathrm{SO}_{2}$ and $\mathrm{NO}_{2}$ and that crystallinity is retained. The differences here may reflect the much longer exposure times or the interaction of the sample containing $\mathrm{H}_{2} \mathrm{~S}$ with ambient air and moisture during transfer of the sample from the storage container to the gas permeability testing apparatus. In particular, Bhattacharya et al.[27] note structure loss at $85 \%$ RH but much lower partial pressures of $\mathrm{H}_{2} \mathrm{~S}$ $(0.002 \mathrm{kPa})$, due to the formation of acidic species. It seems that given the much higher acid 
gas concentrations here, the very short periods of exposure to much lower ambient air humidities during sample transfer was sufficient to cause acidic reactions and structural loss.

\section{Membrane regeneration}

To determine if the loss of permeability for ZIF- 8 could be recovered, the membranes were re-activated by exposure for 24 hours under vacuum to $100^{\circ} \mathrm{C}$ and $200^{\circ} \mathrm{C}$, respectively. Regeneration of the membrane at $100^{\circ} \mathrm{C}$ was ineffective (Figure 8). The use of $200^{\circ} \mathrm{C}$ for 24 hours was able to recover $20-25 \%$ of the membrane performance. However, the regenerated membrane became more rigid and brittle and the membrane color changed from yellow to light brown. The increased rigidity and brittleness of the membrane probably reflects a loss of free volume within the polymer itself, as this has been noted in previous work [42]. This loss in free volume would counteract any restoration in the performance of the ZIF-8 nanoparticles. It is unclear what has led to the change in membrane color, as this has not been observed during similar thermal treatment of the polymer [42]. However, it may indicate aggregation of the ZIF-8 nanoparticles as the surrounding polymer matrix collapses. 


\section{CONCLUSIONS}

Matrimid-based MMMs using a range of nanoparticles were prepared and tested in the presence of $\mathrm{SO}_{2}, \mathrm{H}_{2} \mathrm{~S}$ and NO. The presence of these acid gas impurities led to a fall in gas permeability of all MMMs. The membranes containing carbon or porous organic nanoparticles were the most stable. In particular, membranes containing the porous organic polymer (POP-2) retained a performance level well above that of the base Matrimid after exposure for at least 40 days to $0.75 \mathrm{kPa}$ of either $\mathrm{H}_{2} \mathrm{~S}$, NO or $\mathrm{SO}_{2}$. Further, these membranes showed enhanced selectivity towards $\mathrm{H}_{2} \mathrm{~S}$ and may have potential for $\mathrm{H}_{2} \mathrm{~S}$ separations. The MMMs using MOFs were less stable and measurements of the membrane density and diffraction patterns indicated structural distortion or collapse. These effects were moderate for $\mathrm{Cu}$-BTC, with the performance after exposure to $\mathrm{SO}_{2}$ for 60 days still above that of the base polymeric membrane. Conversely, deterioration of the MMMs containing ZIF-8 was rapid and extreme, with membrane performance falling below that of the pure polymeric system. Regeneration under vacuum at $100^{\circ} \mathrm{C}$ or $200^{\circ} \mathrm{C}$ was ineffective. In industrial practice, the concentration of these impurities may be significantly lower with values of 10 and $50 \mathrm{ppm} \mathrm{SO}_{2}$ and 150-300 ppm NO typical when flue gas desulphurisation is used. This means that the time frame for such effects to appear may be longer. However, the impact is still likely to be observed, over greater timeframes or to a lesser effect.

\section{ACKNOWLEDGEMENT}

This research was partially supported by the Science and Industry Endowment Fund (SIEF), Australia and Grant-in-Aid for Young Scientists (B) (Grant No. 17K14850) from the Ministry of Education, Culture, Sports, Science and Technology of Japan. The X-ray diffraction analysis was performed within the Materials Characterisation and Fabrication Platform (MCFP) at the University of Melbourne and the Victorian Node of the Australian National Fabrication 
Facility (ANFF). The specialist gas infrastructure was funded by the Australian Research Council (LE120100141) and by the Australian Government Education Investment fund and this support is also gratefully acknowledged. 


\section{REFERENCES}

[1] M. Rezakazemi, A. Ebadi Amooghin, M.M. Montazer-Rahmati, A.F. Ismail, T. Matsuura, State-of-the-art membrane based CO2 separation using mixed matrix membranes (MMMs): An overview on current status and future directions, Prog. Polym. Sci., 39 (2014) 817-861.

[2] T.-S. Chung, L.Y. Jiang, Y. Li, S. Kulprathipanja, Mixed matrix membranes (MMMs) comprising organic polymers with dispersed inorganic fillers for gas separation, Prog. Polym. Sci., 32 (2007) 483-507.

[3] G. Dong, H. Li, V. Chen, Challenges and opportunities for mixed-matrix membranes for gas separation, J. Mater. Chem. A, 1 (2013) 4610-4630.

[4] S. Kanehashi, Development of hybrid membranes for carbon capture, Kobunshi Ronbunshu, 73 (2016) 475-490.

[5] C.H. Lau, K. Konstas, C.M. Doherty, S. Kanehashi, B. Ozcelik, S.E. Kentish, A.J. Hill, M.R. Hill, Tailoring physical aging in super glassy polymers with functionalized porous aromatic frameworks for CO2 capture, Chem. Mater., 27 (2015) 4756-4762.

[6] C.H. Lau, K. Konstas, A.W. Thornton, A.C.Y. Liu, S. Mudie, D.F. Kennedy, S.C. Howard, A.J. Hill, M.R. Hill, Gas-separation membranes loaded with porous aromatic frameworks that improve with age, Angew. Chem. Int. Ed., 54 (2015) 2669-2673.

[7] C.H. Lau, X. Mulet, K. Konstas, C.M. Doherty, M.-A. Sani, F. Separovic, M.R. Hill, C.D. Wood, Hypercrosslinked additives for ageless gas-separation membranes, Angew. Chem. Int. Ed., 55 (2016) 1998-2001.

[8] R.W. Baker, Membrane Technology and Applications, McGraw-Hill, New York, 2000.

[9] H.T. Lu, S. Kanehashi, C.A. Scholes, S.E. Kentish, The potential for use of cellulose triacetate membranes in post combustion capture, Int. J. Greenhouse Gas Control, 55 (2016) 97-104.

[10] D. Adams, Flue gas treatment for CO2 capture, in: I.C.C. Centre (Ed.), 2010.

[11] R.W. Baker, K. Lokhandwala, Natural gas processing with membranes: an overview, Ind. Eng. Chem. Res., 47 (2008) 2109-2121.

[12] J.C.M. Farla, C.A. Hendriks, K. Blok, Carbon dioxide recovery from industrial processes, Climatic Change, 29 (1995) 439-461.

[13] K. Thambimuthu, M. Soltanieh, A. J.C., IPCC Special Report on Carbon Dioxide Capture and Storage, in: I.P.o.C. Change (Ed.), Cambridge University Press, Cambridge, 2005.

[14] O.W. Awe, Y. Zhao, A. Nzihou, D.P. Minh, N. Lyczko, A review of biogas utilisation, purification and upgrading technologies, Waste Biomass Valor., 8 (2017) 267-283.

[15] C.A. Scholes, S.E. Kentish, G.W. Stevens, Effects of minor components in carbon dioxide capture using polymeric gas separation membranes, Sep. Purif. Rev., 38 (2009) 1-44.

[16] C. Petit, B. Mendoza, T.J. Bandosz, Hydrogen sulfide adsorption on MOFs and MOF/graphite oxide composites, ChemPhysChem, 11 (2010) 3678-3684.

[17] J. Ethiraj, F. Bonino, C. Lamberti, S. Bordiga, H2S interaction with HKUST-1 and ZIF-8 
MOFs: A multitechnique study, Microporous Mesoporous Mater., 207 (2015) 90-94.

[18] J. Liu, Y. Wei, P. Li, Y. Zhao, R. Zou, Selective H2S/CO2 Separation by Metal-Organic Frameworks Based on Chemical-Physical Adsorption, J. Phys. Chem. C, 121 (2017) 1324913255.

[19] C.J. Anderson, W. Tao, C.A. Scholes, G.W. Stevens, S.E. Kentish, The performance of carbon membranes in the presence of condensable and non-condensable impurities, J. Membr. Sci., 378 (2011) 117-127.

[20] C.A. Scholes, G.Q. Chen, W.X. Tao, J. Bacus, C. Anderson, G.W. Stevens, S.E. Kentish, The effects of minor components on the gas separation performance of membranes for carbon capture, in: Energy Procedia, 2011, pp. 681-687.

[21] G.W. Peterson, J.A. Rossin, J.B. Decoste, K.L. Killops, M. Browe, E. Valdes, P. Jones, Zirconium hydroxide-metal-organic framework composites for toxic chemical removal, Industrial and Engineering Chemistry Research, 52 (2013) 5462-5469.

[22] J.B. DeCoste, T.J. Demasky, B.J. Shindler, J.R. Soliz, M.J. Katz, O.K. Farha, J.T. Hupp, G.W. Peterson, Strategies for the broad spectrum removal of toxic gases by metal-organic frameworks, in, American Chemical Society, 2014, pp. INOR-439.

[23] J. Yu, Y. Ma, P.B. Balbuena, Evaluation of the Impact of $\mathrm{H} 2 \mathrm{O}, \mathrm{O} 2$, and $\mathrm{SO} 2$ on Postcombustion CO2 Capture in Metal-Organic Frameworks, Langmuir, 28 (2012) 8064-8071. [24] W. Sun, L.-C. Lin, X. Peng, B. Smit, Computational screening of porous metal-organic frameworks and zeolites for the removal of SO2 and NOx from flue gases, AIChE J., 60 (2014) 2314-2323.

[25] X.-D. Song, S. Wang, C. Hao, J.-S. Qiu, Investigation of SO2 gas adsorption in metalorganic frameworks by molecular simulation, Inorg. Chem. Commun., 46 (2014) 277-281.

[26] J. Hu, Y. Liu, J. Liu, C. Gu, Effects of water vapor and trace gas impurities in flue gas on $\mathrm{CO} 2$ capture in zeolitic imidazolate frameworks: The significant role of functional groups, Fuel, 200 (2017) 244-251.

[27] S. Bhattacharyya, S.H. Pang, M.R. Dutzer, R.P. Lively, K.S. Walton, D.S. Sholl, S. Nair, Interactions of SO2-Containing Acid Gases with ZIF-8: Structural Changes and Mechanistic Investigations, J. Phys. Chem. C, 120 (2016) 27221-27229.

[28] C. Petit, B. Levasseur, B. Mendoza, T.J. Bandosz, Reactive adsorption of acidic gases on MOF/graphite oxide composites, Microporous Mesoporous Mater., 154 (2012) 107-112.

[29] P. Xu, T. Xu, H. Yu, X. Li, Resonant-Gravimetric Identification of Competitive Adsorption of Environmental Molecules, Anal. Chem. (Washington, DC, U. S.), 89 (2017) 7031-7037.

[30] B. Xiao, Q. Yuan, R.A. Williams, Exceptional function of nanoporous metal organic framework particles in emulsion stabilisation, Chem. Comm., 49 (2013) 8208-8210.

[31] C. Hua, A. Rawal, T.B. Faust, P.D. Southon, R. Babarao, J.M. Hook, D.M. D'Alessandro, Exploiting stable radical states for multifunctional properties in triarylamine-based porous organic polymers, J. Mat. Chem. A, 2 (2014) 12466-12474.

[32] S. Kanehashi, G.Q. Chen, C.A. Scholes, B. Ozcelik, C. Hua, L. Ciddor, P.D. Southon, D.M. 
D'Alessandro, S.E. Kentish, Enhancing gas permeability in mixed matrix membranes through tuning the nanoparticle properties, J. Membr. Sci., 482 (2015) 49-55.

[33] S. Kanehashi, G.Q. Chen, L. Ciddor, A. Chaffee, S.E. Kentish, The impact of water vapor on CO2 separation performance of mixed matrix membranes, J. Membr. Sci., 492 (2015) 471 477.

[34] G.Q. Chen, C.A. Scholes, G.G. Qiao, S.E. Kentish, Water vapor permeation in polyimide membranes, J. Membr. Sci., 379 (2011) 479-487.

[35] C.A. Scholes, S. Kanehashi, G.W. Stevens, S.E. Kentish, Water permeability and competitive permeation with $\mathrm{CO} 2$ and $\mathrm{CH} 4$ in perfluorinated polymeric membranes, Sep. Purif. Technol., 147 (2015) 203-209.

[36] I. 19702, Guidance for sampling and analysis of toxic gases and vapours in fire effluents using Fourier Transform Infrared (FTIR) spectroscopy, in, International Organization for Standardization, 2015.

[37] G.Q. Chen, S. Kanehashi, C.M. Doherty, A.J. Hill, S.E. Kentish, Water vapor permeation through cellulose acetate membranes and its impact upon membrane separation performance for natural gas purification, J. Membr. Sci., 487 (2015) 249-255.

[38] C.Y. Pan, Gas separation by high-flux, asymmetric hollow-fibre membrane, AIChE Journal, 32 (1986) 2020-2027.

[39] B.E. Poling, J.M. Prausnitz, J.P. O'Connell, The Properties of Gases and Liquids, 5th Ed ed., Fifth Ed., McGraw-Hill, New York, 2000.

[40] C. Petit, T.J. Bandosz, Exploring the coordination chemistry of MOF-graphite oxide composites and their applications as adsorbents, Dalton Trans., 41 (2012) 4027-4035.

[41] S. Kanehashi, T. Nakagawa, K. Nagai, X. Duthie, S. Kentish, G. Stevens, Effects of carbon dioxide-induced plasticization on the gas transport properties of glassy polyimide membranes, J. Membr. Sci., 298 (2007) 147-155.

[42] X. Duthie, S. Kentish, S.J. Pas, A.J. Hill, C. Powell, K. Nagai, G. Stevens, G. Qiao, Thermal treatment of dense polyimide membranes, Journal of Polymer Science Part B-Polymer Physics, 46 (2008) 1879-1890. 


\section{Figure Captions}

Figure 1. $\quad \mathrm{N}_{2}$ permeability of fresh Matrimid and mixed matrix membranes under pure $\mathrm{N}_{2}$ and 1000 ppm of $\mathrm{H}_{2} \mathrm{~S}, \mathrm{SO}_{2}$ and $\mathrm{NO}$ in $\mathrm{N}_{2}$ at $35^{\circ} \mathrm{C}$ and 7.5 bar feed pressure (0.75 kPa of the contaminant).

Figure 2. Photographs of the mixed matrix membrane containing $20 \mathrm{wt} \% \mathrm{Cu}$-BTC (a) fresh; (b) after $\mathrm{H}_{2} \mathrm{~S}$ permeation; and (c) after 30 days under $\mathrm{H}_{2} \mathrm{~S}$.

Figure 3. The $\mathrm{N}_{2}$ and $\mathrm{CH}_{4}$ permeability of Matrimid and mixed matrix membranes after long term exposure to 1000 ppm of $\mathrm{H}_{2} \mathrm{~S}$ in $\mathrm{N}_{2}$ at $7.5 \mathrm{Bar}\left(0.75 \mathrm{kPa} \mathrm{H}_{2} \mathrm{~S}\right.$ partial pressure).

Figure 4. The $\mathrm{N}_{2}$ and $\mathrm{CH}_{4}$ permeability of Matrimid and mixed matrix membranes after long term exposure to $1000 \mathrm{ppm}$ of $\mathrm{NO}$ in $\mathrm{N}_{2}$ at $7.5 \mathrm{Bar}(0.75 \mathrm{kPa} \mathrm{NO}$ partial pressure).

Figure 5. The $\mathrm{N}_{2}$ and $\mathrm{CH}_{4}$ permeability of Matrimid and mixed matrix membranes after long term exposure to 1000 ppm of $\mathrm{SO}_{2}$ in $\mathrm{N}_{2}$ at $7.5 \mathrm{Bar}\left(0.75 \mathrm{kPa} \mathrm{SO}_{2}\right.$ partial pressure).

Figure 6. The density of Matrimid and mixed matrix membranes after exposure to pure $\mathrm{N}_{2}$, and mixtures of 1000 ppm of $\mathrm{H}_{2} \mathrm{~S}, \mathrm{NO}$, and $\mathrm{SO}_{2}$ in $\mathrm{N}_{2}$ for 20 to 80 days.

Figure 7. Wide angle X-ray Diffraction patterns of ZIF-8 after aging for 20 to 30 days in (a) $\mathrm{N}_{2}$; (b) 1000 ppm of $\mathrm{H}_{2} \mathrm{~S}$; (c) 1000 ppm of $\mathrm{SO}_{2}$; (d) 1000 ppm of NO.

Figure 8. The nitrogen permeability of a mixed matrix membrane containing $20 \mathrm{wt} \%$ ZIF-8, both fresh, aged in $1000 \mathrm{ppm}$ of $\mathrm{SO}_{2}$ and after regeneration at $100^{\circ} \mathrm{C}$ and $200^{\circ} \mathrm{C}$. 


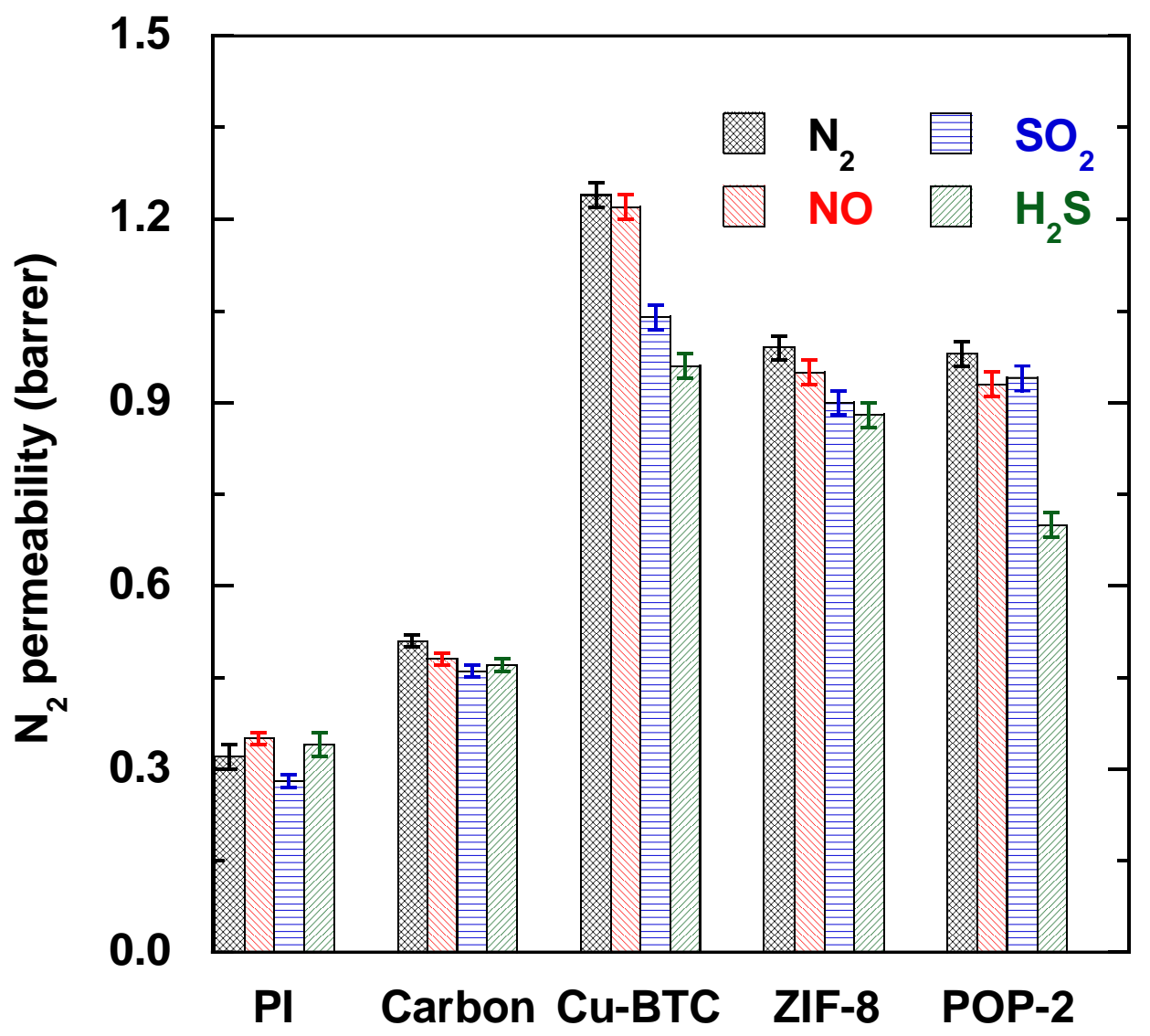

Figure 1 (Kanehashi et al.) 


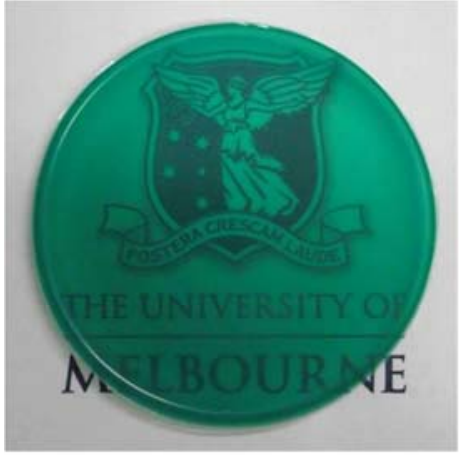

Fresh

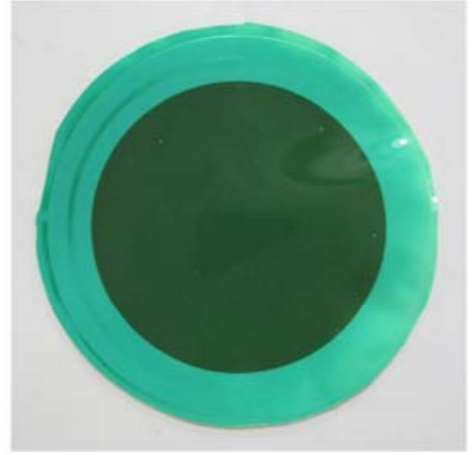

After Initial

Permeation test

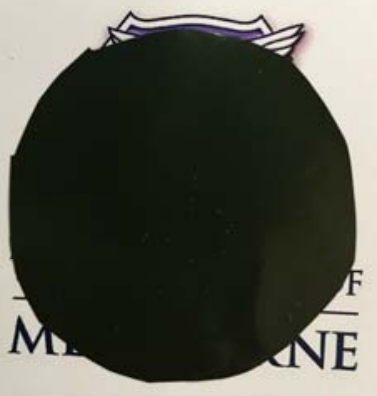

After 30 days under $\mathrm{H}_{2} \mathrm{~S}$ 

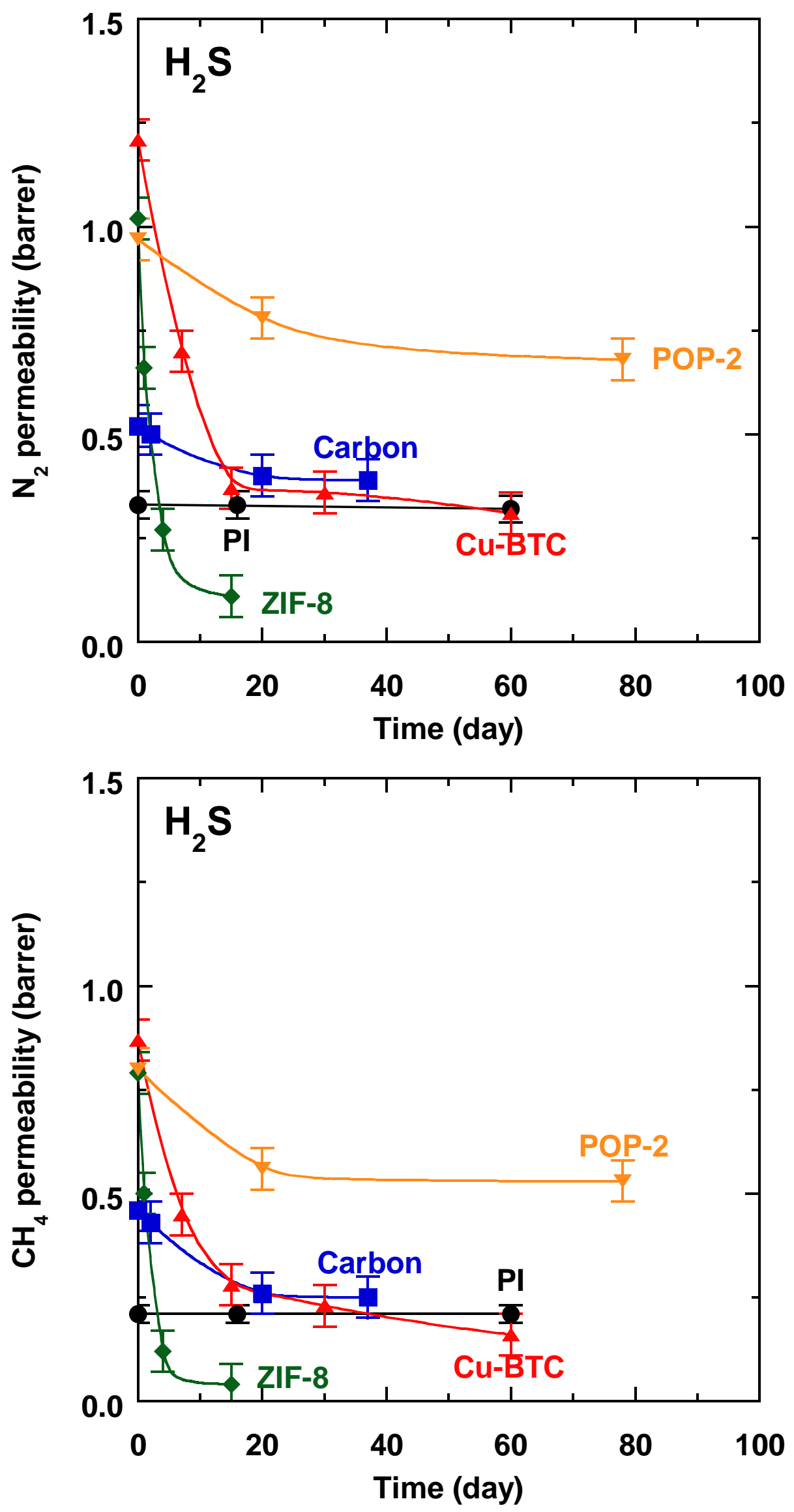

Figure 3 (Kanehashi et al.) 

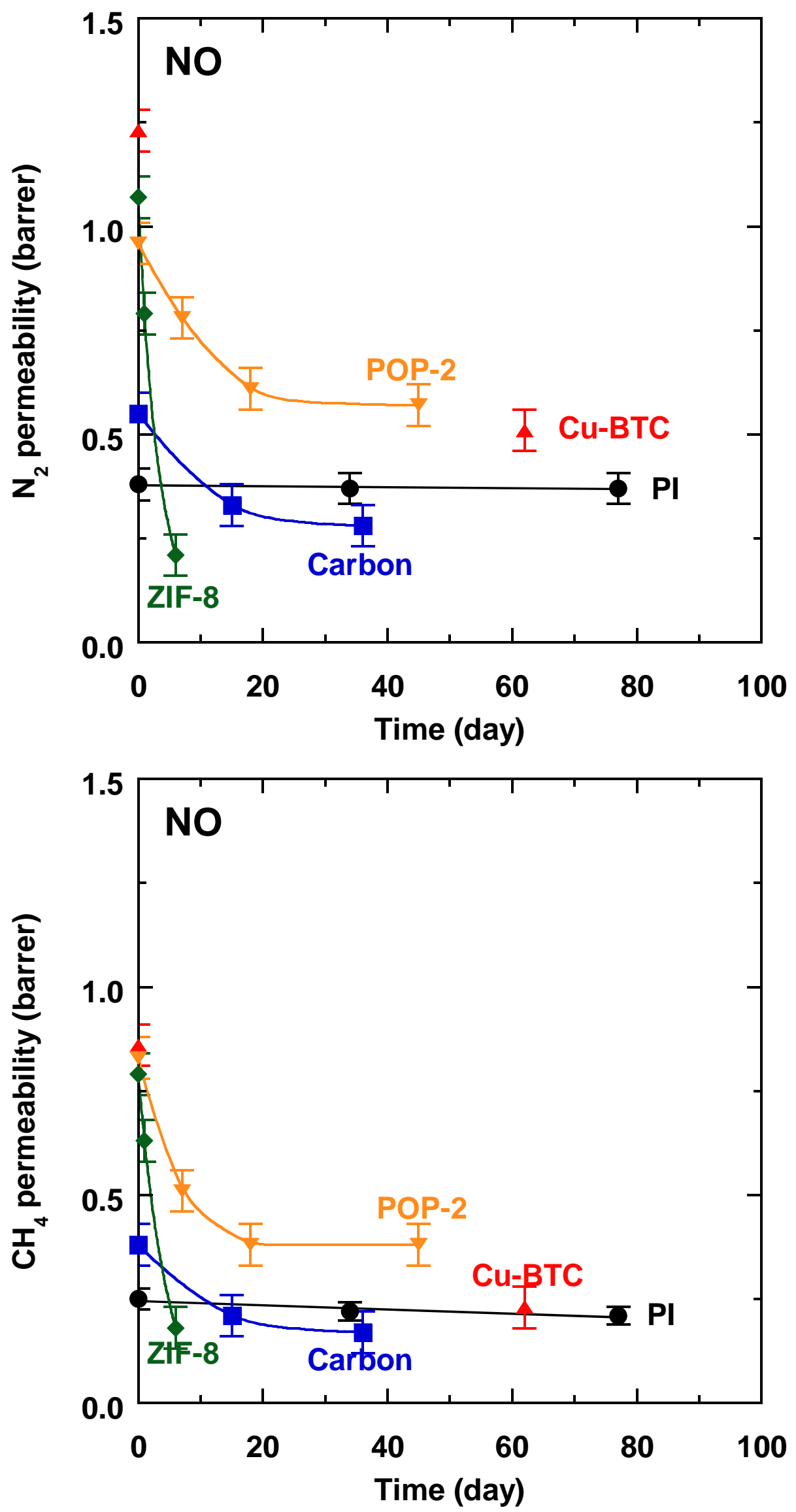

Figure 4 (Kanehashi et al.) 

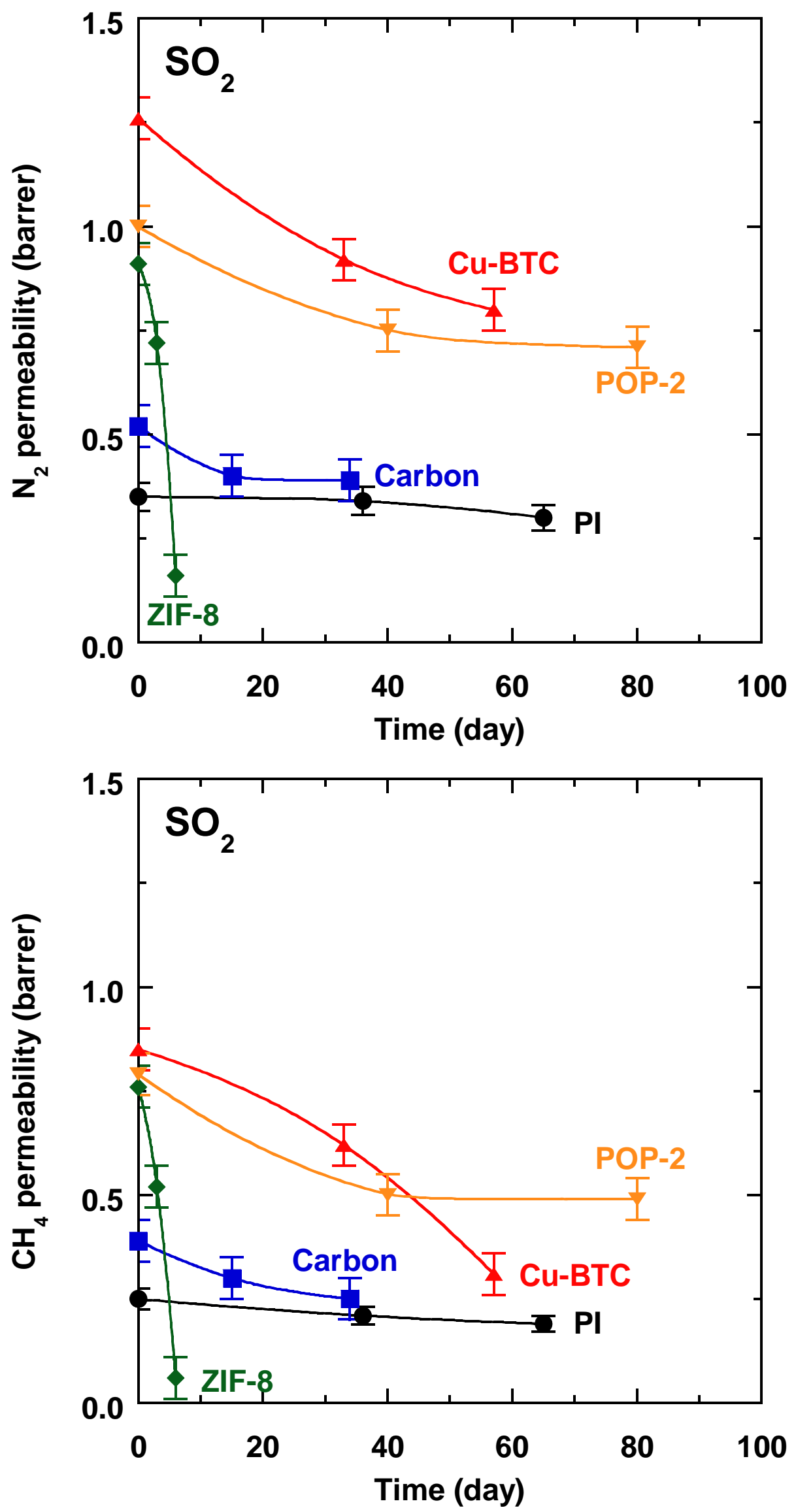

Figure 5 (Kanehashi et al.) 


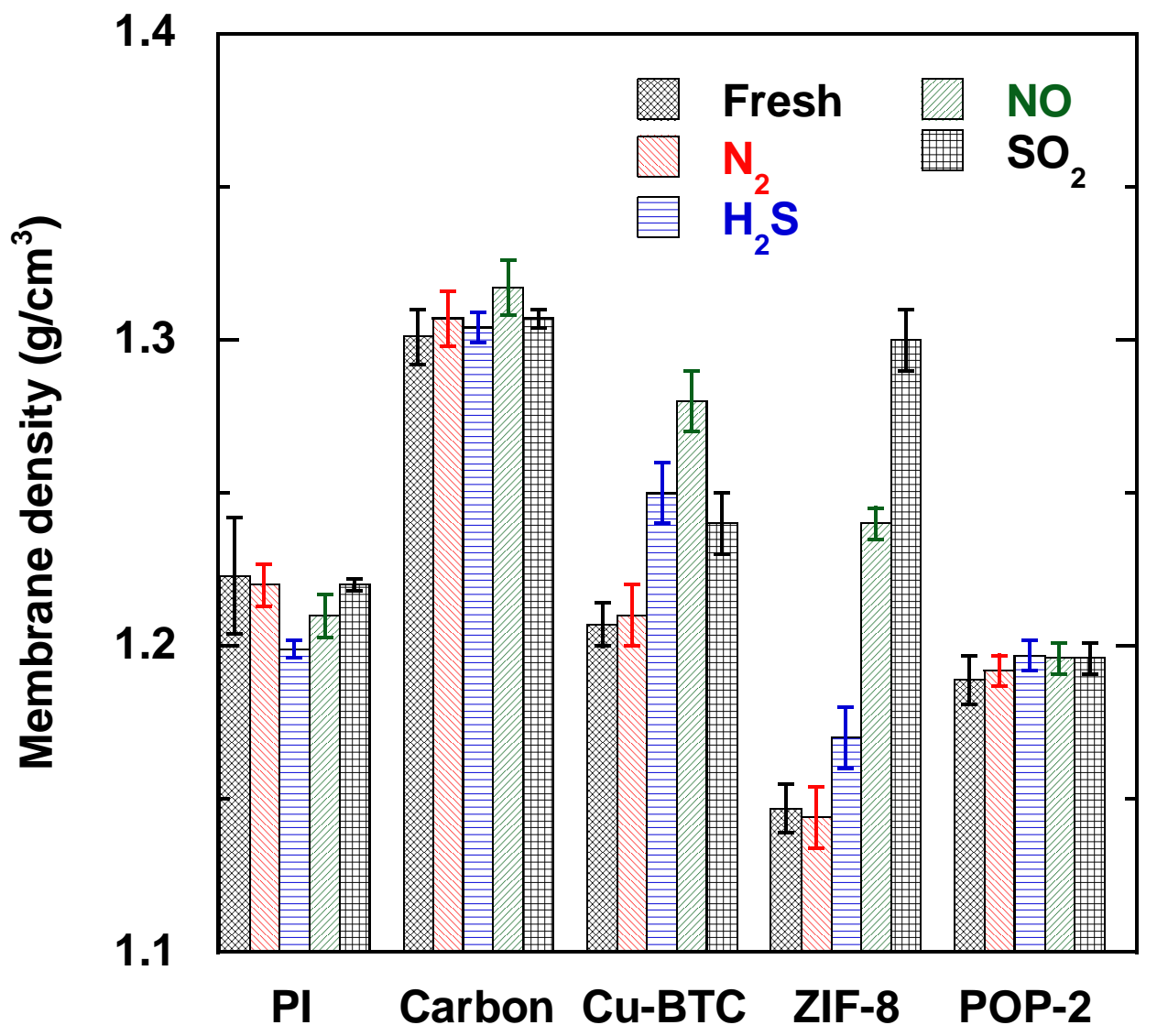

Figure 6 (Kanehashi et al.) 

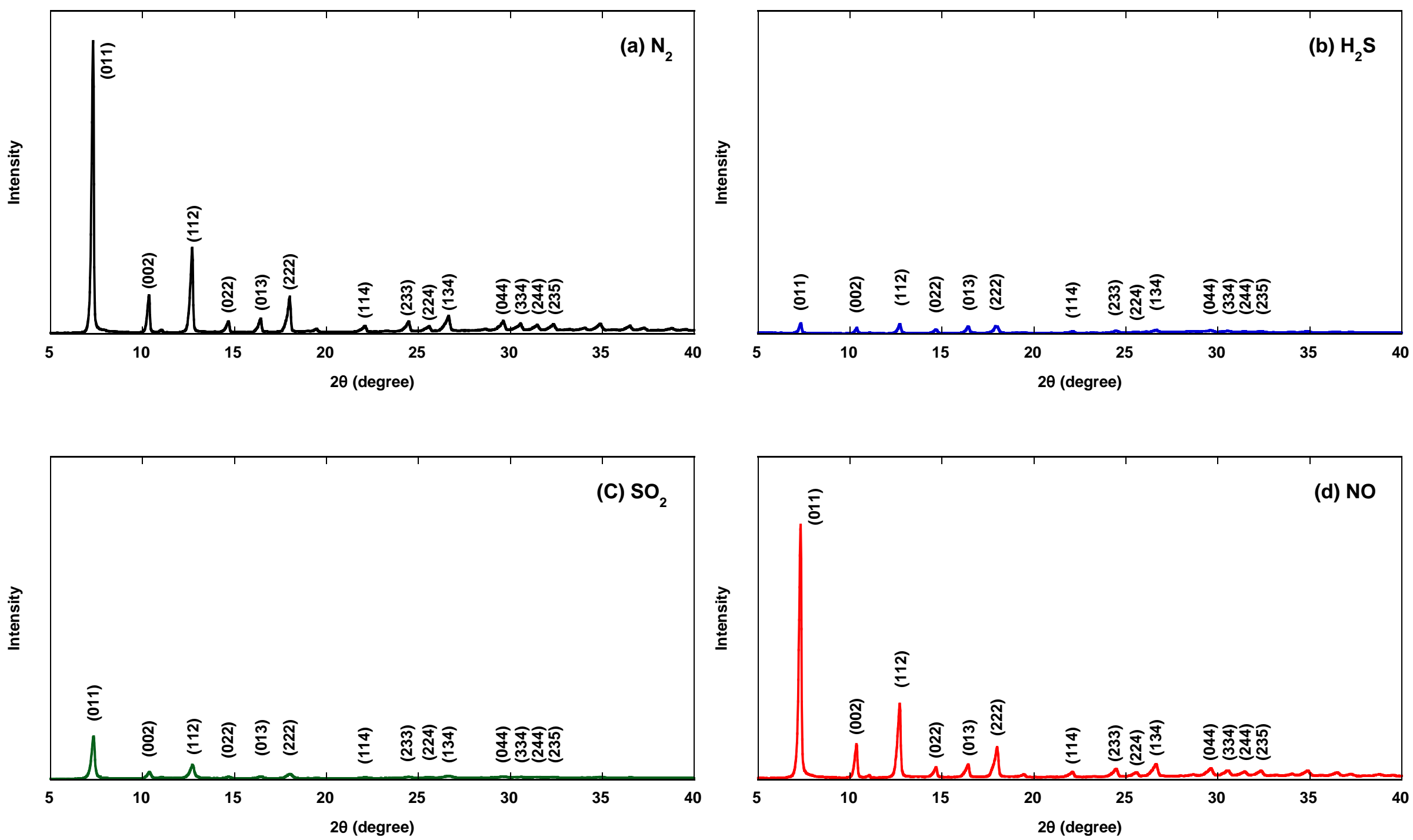

Figure 7 (Kanehashi et al.) 


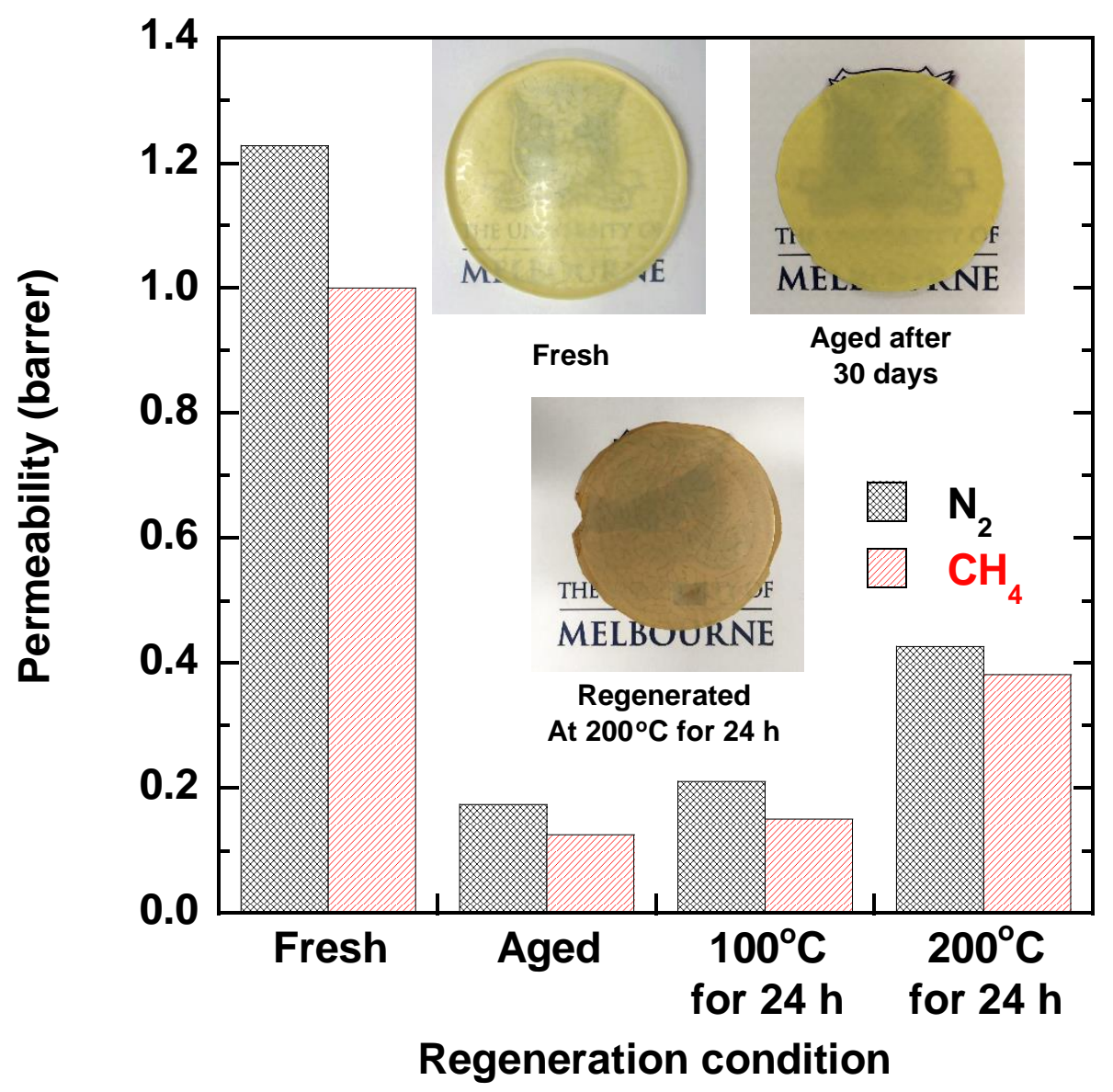

Figure 8 (Kanehashi et al.) 
Table 1 Permeability of a range of gases through the mixed matrix membranes

\begin{tabular}{|c|c|c|c|c|c|c|}
\hline Gas measured & Feed gas & Matrimid & Carbon & ZIF-8 & $\mathrm{Cu}-\mathrm{BTC}$ & POP-2 \\
\hline $\mathrm{CO}_{2}{ }^{(\mathrm{a})}$ & Pure & $7.3 \pm 0.6$ & $15.0 \pm 0.4$ & $27.8 \pm 0.6$ & $31.7 \pm 1.4$ & $26.9 \pm 1.0$ \\
\hline $\mathrm{CH}_{4}$ & Pure & $0.21 \pm 0.01$ & $0.43 \pm 0.04$ & $0.78 \pm 0.02$ & $0.86 \pm 0.01$ & $0.75 \pm 0.02$ \\
\hline $\mathrm{N}_{2}$ & Pure & $0.32 \pm 0.02$ & $0.51 \pm 0.01$ & $0.99 \pm 0.02$ & $1.24 \pm 0.02$ & $0.98 \pm 0.02$ \\
\hline $\mathrm{N}_{2}$ & $\begin{array}{c}1000 \mathrm{ppm} \mathrm{H}_{2} \mathrm{~S} \\
\text { in } \mathrm{N}_{2}\end{array}$ & $0.34 \pm 0.02$ & $0.47 \pm 0.01$ & $0.88 \pm 0.02$ & $0.96 \pm 0.02$ & $0.70 \pm 0.02$ \\
\hline $\mathrm{H}_{2} \mathrm{~S} / \mathrm{CH}_{4}{ }^{(b)}$ & - & 16.0 & 18.8 & 6.9 & 0 & 17.8 \\
\hline $\mathrm{H}_{2} \mathrm{~S} / \mathrm{N}_{2}{ }^{(b)}$ & - & 10.5 & 15.9 & 5.5 & 0 & 13.6 \\
\hline $\mathrm{H}_{2} \mathrm{~S} / \mathrm{N}_{2}{ }^{(c)}$ & - & 9.9 & 17.2 & 6.2 & 0 & 19.1 \\
\hline
\end{tabular}

(a) Cited from [30]

(b) Based on the permeability of $\mathrm{CH}_{4}$ and $\mathrm{N}_{2}$ as the pure gas, relative to $\mathrm{H}_{2} \mathrm{~S}$ in the mixture with $\mathrm{N}_{2}$

(c) Based on the permeability of both gases in the mixture 